\title{
The Choice of Tense in Translation into the Second Language
}

\author{
Meng-Lin Chen ${ }^{1} \&$ Dahui Dong ${ }^{1 *}$ \\ ${ }^{1}$ Department of Translation and Interpretation Studies, Chang Jung Christian University, Taiwan \\ *Dahui Dong, E-mail: dongdahui @ mail.cjcu.edu.tw
}

\begin{abstract}
English tense is widely believed as one of the most problematic areas in the "interlanguage", which includes non-native English speakers' English writing and translations into the translator's second language. This study aims to investigate the relationships between the tense choice in translation, the tense in the Chinese source text, and the translation competence of translators. A small Chinese-English parallel corpus has been built with 127 translations of Chinese press editorials by experienced native English speaking translators, experienced native Chinese speaking translators, and novice native Chinese speaking translators. Cross-tabulate analyses of this study have shown that the three groups of translators differ from one another significantly in their handling of marked Chinese past tense verbs, while they do not when translating Chinese sentences with contextually marked tense. This study suggests that in order to improve their translation quality, (1) experienced native Chinese speaking translators need to increase the percentages of Present Simple, Present Progress, Present Perfect, and Past Simple, and reduce the percentages of Past Perfect in their translation; (2) novice native Chinese speaking translators need to increase the percentages of Present Simple, and Present Progress, and reduce the percentages of Past Perfect, Past Simple, and Present Perfect in their translation.
\end{abstract}

\section{Keywords}

Chinese into English Translation, translation into the second language, Chinese-English Corpus, tense Choice in Translation

\section{Introduction}

English tense is widely believed as one of the most problematic areas in interlanguage, which includes non-native English speakers' English writing and translation into English (Bardovi-Harlig, 1995; El-Dash \& Busnardo, 2003; Guiora, 1983; Hawes \& Thomas, 1995, 1997; Hinkel, 1992; Lackstrom et al., 1973; Lackstrom et al., 1988; McCarthy, 1991; Oster, 1981; Schramm, 1996; Yang \& Huang, 2004; Zydatiss, 1986). Studies have found that the choice of tense in non-native speakers' writing is related with their English proficiency (Andersen, 1991; Bardovi-Harlig, 1995, 1998; El-Dash \& Busnardo, 2003; Schramm, 1996; Vlach, 1993; Yang \& Huang, 2004). Many studies focus on enhancing the understanding of interlanguage with many researchers making efforts to study the contribution of tense in interlanguage. It has been found that the distribution of tenses in interlanguage could be used as an 
assessment criterion of English proficiency based on an exhibition of a sequence from pragmatic to lexical to grammatical devices (Bardovi-Harlig, 1999, 2000). In other words, in the earlier stage, learners tend to rely on chronological order to express time reference. In the second stage, they rely more on adverbial expressions (e.g., yesterday, today) and connectives (e.g., therefore). In the third stage, they rely more on verbal morphology to express temporal reference. With the improvement of English proficiency, the distribution of tense in a learner's writing could gradually match that of a native English speaker (Chen, 2005).

According to Campbell (1998), translators into the second language can be regarded as learners of the language. Being a learner of a language means that the language produced by such a person is always a kind of "interlanguage", which is on an evolutionary path to the norm of that language (Selinker, 1969). Therefore, it can be expected that translations by native Chinese translators in this study would be subject to the influence from the first language and carry similar characteristics of the "interlanguge" like ESL writings.

A number of studies have looked at the tense choice and translation competence. El-Dash and Busnardo (2003: 1823) look at the translation of verb tenses from English into Portuguese. They find that over $70 \%$ of the inflected English verb forms require careful interpretation "despite the superficial similarity of verb tense forms" in the two languages. They further conclude that the verb tense choice is part of the translator's pragmatic competence, which is "an important part of a general competence in translation" (El-Dash \& Busnardo, 2003: 1838). But the study does not provide further information on how the pragmatic competence of choosing verb accounts for translation competence. In his study of translation competence into the second language, Campbell (1998) proposes a model of translation competence, a part of which deals with the translator's language competence. It is defined as "textual competence" and can be represented by features presented in the translation such as nominalization, average word length, diversity of vocabulary (e.g., type/token ratio), agentless passives, and prepositional phrases. Obviously, these are only five basic textual features of the translation, and the translator's choice of tense together with many other important features such as cohesion devices should have been included as the author himself points out. Therefore, this study was focused on how the $\mathrm{L} 1$ and the source text influenced the translator when he/she chose the tense.

It is well known that temporal reference in Chinese is not expressed through verbal morphology, which is different from that in English. Chinese expresses its temporal reference through temporal adverbs (tense markers) such as qu nian (last year), ming nian (next year), and zuo tian (yesterday), or through aspectual markers such as le and guo, or through the context (Lin, 2006; Maia, 2003; Wong et al., 2002).

Yang and Huang (2004) provide a more detailed analysis of Chinese tense and find that they can be expressed in the following ways:

1) temporal adverbials, including deictic temporal expressions like long ago, yesterday, etc.;

2) anaphoric adverbials like after; before, at the time, on that day, the next day, etc.; 
3) calendric temporal phrases like in 1993; last Sunday, etc.;

4) temporal adverbial clauses introduced by when, after, before, while, etc.;

5) other temporal expressions like in my primary school years, etc.; and

6) frequency adverbials like always, often.

And in some cases, as reported by Lin (2006), Chinese sentences resort to neither tense and aspectual markers nor the context to determine their temporal reference.

The difference between the two languages in expression of temporal reference has been found to exert profound influence on native Chinese speakers' use of English tense, resulting in them to take a long time to acquire the proper usage of English tense. For example, having studied 5 groups of a total 453 native Chinese speaking English as Second Language (ESL) learners in Hong Kong ranging from grade 5 (10 years old) to university year 1 (19 years old), Yang and Huang (2004) have found that these learners show a very slow shift from depending more on Chinese way of expressing temporal reference (using more pragmatic and lexical devices in writing) to depending more on the English way (using more grammatical devices in writing). Similar results have been reported in studies of ESL learners with different first languages (Bardovi-Harlig, 1998; Bardovi-Harlig \& Bergstrom, 1996; Collins, 2005; Coppieters, 1987; Guiora, 1983; Hinkel, 1992, 1997; Liszka, 2004). It is particularly important to note that the same pattern even applies to learners who have acquired near-native like proficiency (Coppieters, 1987). These studies indicate that no matter how advanced a native Chinese speaking learner may be in English proficiency, he/she may still be influenced by the Chinese language tense system when choosing English tenses. This current study, therefore, selected translators of three different language competence levels: native Chinese novice translators (lower English competence), native Chinese experienced translators (higher English competence), and native English experienced translators (highest English competence). By comparing the characteristics of their tense distribution in translation, the study is expected to shed some light on how the tense choice differs among translators of different translation competence and provide guidelines for translators of lower competence levels to improve. Focused on the study of translation into the second language (Campbell, 1998; Lonsdale, 2001; Presas, 2000), this study further allows new insight into factors that influence the choice of tense with a comparison of native English speaking translators and native Chinese speaking translators.

From the above literature review, it seems that translators of different translation competence levels could differ in their choice of tense in translation from Chinese into English. Therefore, this study aims to investigate the relationships between the tense choice in translation, the tense in the Chinese source text, and the translation competence of translators. It answers the following two research questions: 1) What are the characteristics of English tense choices by translators of three competence levels when they translate source texts that contain tense markers? Are there differences among the translators?

2) What are the characteristics of English tense choices by translators of three competence levels when they translate source texts that contain no tense markers? Are there differences among the translators? The first question concerns with the influence of the translation competence on the use of tense in the 
target text. The second question concerns with the influence of the source text on the use of tense in the target text.

\section{Method}

Sixteen experienced native English speaking translators and twenty-two experienced native Chinese speaking translators were recruited, who had been working as freelance translators or teachers of translation for at least 3 years in Taiwan or Australia. Another 28 novice native Chinese speaking translators were recruited from graduate students of universities in Taiwan, who majored in translation or applied languages (English) but had limited real world translation experience. The study reported here extracted 127 translations produced by the subjects on the topic of economics and trade. A total of 48 source texts were translated. In order to make the study easier, the parallel corpus was aligned from the 127 translations at the sentence level using Trados 7.0, a machines assisted translation software. The output from this program was then corrected by hand to ensure accurate alignment. The aligned corpus contains 707 translation pairs.

The 707 translation pairs were coded for the translator's competence level, the tense of the source sentence, the expression of the tense in the source text, and tense of the target sentence. The details of the process are outlined as follows:

1) The translator's competence level (Competence): translators were divided into three competence levels: experienced native English speaking (NS experienced) $=1$; experienced native Chinese speaking $($ NNS experienced $)=2$; and novice native Chinese speaking $($ NNS novice $)=3$;

2) The choice of tense (Target Tense): the five most frequent used tense and aspect combinations in English editorials were classified, which included the past simple, past perfect, present simple, present perfect, and present progress;

3) The corresponding Chinese tense (Source Tense): the tense in the Chinese clause was searched by hand and coded with the help of a concordance function provided by Trados 7.0. Three tenses were coded: present, past and future.

4) The expression of the tense in Chinese texts (Chinese Tense Expression): based on the methods proposed by Wong et al. (2002), Lin (2006) and Yang and Huang (2004) to define the expression of Chinese tenses, this study divided the expression of tense in Chinese sentences into two types: Type I, sentences that contain temporal adverbials, deictic expressions, and aspectual markers. Type I sentences were coded as "Marked"; and Type II, sentences that contain no temporal adverbials or aspectual markers, and the tense of which is determined by the context. Type II sentences were coded as "Context". 


\section{Results}

We selected the source texts that contain tense markers from the corpus, and an analysis of the two variables, "Competence" and "Target Tense \& Aspect" showed that translators of different groups differ significantly $\left(X^{2}=23.672 ; \mathrm{df}=8\right.$; sig. $\left.=0.003\right)$ in terms of their choices of tense and aspect in translation. Table 1 shows that:

1) only NNS translators used past perfect, and the NS translators did not;

2) translators of higher competence levels tended to use fewer past simple;

3) experienced translators (both NS and NNS experienced) used less present perfect than novice translators;

4) NS experienced and NNS novice translators used more present progressive than NNS experienced translators;

5) experienced translators used more present simple than novice translators.

Table 1. Choices of Tense and Aspect by Different Groups

\begin{tabular}{ll}
\hline Target Tense \& Aspect & Translators' Choices \\
\hline Past Perfect & NS exp. (0) $<$ NNS exp. $(0.22 \%)=$ NNS novice $(0.22 \%)$ \\
Past Simple & NS exp. $(3.2 \%)<$ NNS exp. $(4.4 \%)<$ NNS novice $(5.9 \%)$ \\
Present Perfect & NS exp. $(21.1 \%) \sim$ NNS exp. $(21.2 \%)<$ NNS novice $(38.8 \%)$ \\
Present Progressive & NNS exp. $(1.8 \%)<$ NNS novice $(4.6 \%) \sim$ NS exp. $(4.7 \%)$ \\
Present Simple & NNS novice $(50 \%)<$ NS exp. $(71.1 \%) \sim$ NNS exp. $(71.7 \%)$ \\
\hline
\end{tabular}

It appears that NNS experienced translators and NNS novice translators resort to all the 5 tense-aspect forms investigated in this study. However, the percentage of each tense-aspect form occurring in their translations is different except for past perfect at the first glance. Further Chi-square tests need to be carried out to find whether the differences are significant. In the exceptional case of past perfect, the major reason for both novice and experienced NNS translators to use the same amount of past perfect may be that past perfect itself is not commonly used in editorials as we can see from its zero occurrences in the NS experienced translators' translation. In addition, past perfect is difficult for non-native English speakers in general, which may suggest that both novice and experienced NNS translator are not quite confident about its usages.

We then selected the source texts that did not contain tense markers from the corpus, and another Chi-square test was carried out to test the two variables, "Competence" and "Target Tense \& Aspect". The result showed that translators of different groups did not differ significantly $(\mathrm{X} 2=8.785 ; \mathrm{df}=8$; sig. $=0.361)$ in terms of their choice of all the five tense and aspect in translation. However, we still listed the differences among the three translator groups in Table 2. 
Table 2. Chi-Square Test of Differences in the Choice of Tense and Aspect

\begin{tabular}{ll}
\hline Target Tense \& Aspect & Translators' Choices \\
\hline Past Perfect & NS exp. $(0)=$ NNS exp. $(0)<$ NNS novice $(2.1 \%)$ \\
Past Simple & NS exp. $(7.9 \%)<$ NNS novice $(12.8 \%)<$ NNS exp. $(14 \%)$ \\
Present Perfect & NNS novice $(8.5 \%)<$ NNS exp. $(14 \%)<$ NS exp. $(15.8 \%)$ \\
Present Progressive & NNS novice $(0 \%)<$ NS exp. $(1 \%) \sim$ NNS exp. $(1.8 \%)$ \\
Present Simple & NNS exp. $(70.2 \%)<$ NS exp. $(75.2 \%)<$ NNS novice $(76.6 \%)$ \\
\hline
\end{tabular}

As this study assumes that the translation competence of the NS experienced is the highest, followed by NNS experienced and NNS novice, it is suggested that in order to improve translation competence, NNS experienced translators need to increase their use of Present Simple, Present Progress, Present Perfect, and Past Simple, and reduce their use of Past Perfect, while NNS novice translators need to increase their use of Present Simple, and Present Progress, and reduce their use of Past Perfect, Past Simple, and Present Perfect.

\section{Discussion}

It has been claimed that the present tense is predominant in English press editorials (Bolivar, 1994). The results of this study show that it is likely the same in Chinese editorials as present simple occurs most frequently in translation. When the Chinese tense is marked, there is little difference between the NNS and NS experienced translators in their choice of present simple and present perfect (Table 1). The greatest difference between them is their choice of present progressive.

The choice of past simple looks like the only indicator of the translation competence: the use of past tense by NNS novice translators is the highest (5.9\%), followed by the NNS experienced (4.4\%) and NS experienced (3.2\%). The difference between native English and native Chinese speaking translators in the use of past simple may be resulted from their different understanding of English past tense. As Riddle (1986) points out, the use of English tense is not completely dependent on time. Native English speakers could use either past simple or present perfect to refer to events that occurred in the past, while the Chinese often lack understanding of the meaning of English tenses (Bardovi-Harlig, 1995; Chen, 2005; Hinkel, 1992, 2004). Although the appropriateness of native English speaking translators' choice of other tense-aspect forms to translate marked past tense in Chinese should be subject to further inquiry, the results at least show that native English speaking translators have a wider variety of tense choices compared with the Chinese ones. In this sense, it is imperative that native Chinese speaking translators pay more attention to this in order to improve their translation from Chinese into English.

The results are also in consistent with findings of ESL studies, which state that the insufficient understanding of English tenses is limited to learners of low proficiency but widely exists in the writings of learners of high or near native like proficiency (Coppieters, 1987; Hinkel, 1992, 1997). It 
appears from the results that this problem could also present in the translation of native Chinese speaking translators who were usually considered as competent in both languages.

\section{Concluding Remarks}

This study suggests that native English speaking translators have better understanding of pragmatic or semantic meaning of past tense than the Chinese translators, which enables them to choose from a variety of tenses to express their point of view of a translation situation according to their rhetorical needs. Based on the findings, this study concludes that native Chinese speaking translators need pay more attention to the different meanings of tense when translating Chinese tenses, particularly marked past tense.

\section{References}

Bardovi-Harlig, K. (1995). A Narrative Perspective on the Development of the Tense/Aspect System in Second Language Acquisition. Studies in Second Language Acquisition, 17(2), 263-291.

Bardovi-Harlig, K. (1998). Narrative Structure and Lexical Aspect: Conspiring Factors in Second Language Acquisition of Tense-Aspect Morphology. Studies in Second Language Acquisition, 20(4), 471-508.

Bardovi-Harlig, K. (1999). From morpheme studies to temporal semantics. Studies in Second Language Acquisition, 21, 341-382.

Bardovi-Harlig, K. (2000). Tense and Aspect in Second Language Acquisition: Form, Meaning and Use. Oxford: Blackwell.

Bardovi-Harlig, K., \& Bergstrom, A. (1996). Acquisition of Tense and Aspect in Second Language and Foreign Language Learning: Learner Narratives in ESL and FFL. The Canadian Modern Language Review/La Revue canadienne des langues vivantes, 52(2), 308-330.

Bolivar, A. (1994). The Structure of Newspaper Editorials. In M. Coulthard (Ed.), Advances in Written Text Analysis (pp. 276-294). London and New York: Routledge.

Campbell, S. (1998). Translation into the second language. London: Longman.

Chen, Y.-C. (2005). Chinese Speakers' Use of Tense and Aspect in an English Past-time Context. English Teaching and Learning, 29(4), 87-105.

Collins, L. (2005). Accessing Second Language Learners' Understanding of Temporal Morphology. Language Awareness, 14(4), 207-220.

Coppieters, R. (1987). Competence Differences between Native and Non-native Speakers. Language, 63, 544-573.

El-Dash, L. G., \& Busnardo, J. (2003). Interaction of Semantic and Pragmatic Choices in the Translation of Verb Forms: English and Portuguese. Journal of Pragmatics, 35(12), 1823-1841.

Guiora, A. (1983). The dialectic of language acquisition. Language Learning, 33, 3-12.

Hawes, T., \& Thomas, S. (1995). Theme Choice and Lateral Verbs in Newspaper Editorials. Hongkong Published by SCHOLINK INC. 
Papers in Linguistics \& Language Teaching, 18, 103-113.

Hawes, T., \& Thomas, S. (1997). Tense Choices in Citations. Research in the Teaching of English, 31(3), 393-414.

Hinkel, E. (1992). L2 Tense and Time Reference. TESOL Quarterly, 26(3), 557-572.

Hinkel, E. (1997). The Past Tense and Temporal Verb Meanings in a Contextual Frame. TESOL Quarterly, 31(2), 289-313.

Lackstrom, J. et al. (1973). Technical rhetorical principles and grammatical choice. TESOL Quarterly, 7, 127-136.

Lackstrom, J. et al. (1988). Grammar and Technical English. In J. Swales (Ed.), Episodes in ESP. Englewood Cliffs, NJ: Prentice Hall.

Lin, J. W. (2006). Time in a Language without Tense: The Case of Chinese. Journal of Semantics, 23(1), $1-53$.

Liszka, S. A. (2004). Exploring the Effects of First Language Influence on Second Language Pragmatic Processes from a Syntactic Deficit Perspective. Second Language Research, 20(3), 212-231.

Lonsdale, A. B. (2001). Direction of translation (directionality). In M. Baker (Ed.), Routledge Encyclopedia of Translation Studies (pp. 63-67). London: Routledge.

Maia, B. (2003). Some languages are more equal than others. Training translators in terminology and information retrieval using comparable and parallel corpora. In F. Zanettin, S. Bernardini, \& D. Stewart (Eds.), Corpora in Translator Education (pp. 43-53). Manchester: St Jerome.

McCarthy, M. (1991). Discourese Analysis for Language Teachers. Cambridge UK: Cambridge University Press.

Oster, S. (1981). The use of tenses in "reporting past literature" in EST. In L. Selinker, E. Tarone, \& V. Hanzeli (Eds.), English for academic and technical purposes. Rowley, Mass: Newbury House Publishers.

Presas, M. (2000). Bilingual and Translation Competence. In C. Schäffner, \& B. Adab (Eds.), Developing Translation Competence (Vol. 38, pp. 19-31). Armsterdam/Philadelphia: John Benjamins Publishing Company.

Riddle, E. (1986). The Meaning and Discourse Function of the Past Tense in English. TESOL Quarterly, 20(2), 267-286.

Schramm, A. (1996). Using Aspect to Express Viewpoint in EST Texts. English for Specific Purposes, 15(2), 141-164.

Selinker, L. (1969). Language Transfer. General Linguistics, 9(2), 67-92.

Vlach, F. (1993). Temporal adverbials, tenses and the perfect. Linguistics and Philosophy, 16(3), $231-283$.

Wong, K. F. et al. (2002). Temporal Representation and Classification in Chinese. International Journal of Computer Processing of Oriental Languages, 15(2), 211-230.

Yang, S., \& Huang, Y. Y. (2004). The impact of the absence of grammatical tense in L1 on the Published by SCHOLINK INC 
acquisition of the tense-aspect system in L2(1). IRAL, International Review of Applied Linguistics in Language Teaching, 42(1), 49.

Zydatiss, W. (1986). Grammatical categories and their text functions-Some implications for the content of reference grammars. In G. Leitner (Ed.), The English Reference Grammar: Language and Linguistics, Writers and Readers (pp. 140-155). Tübingen: Max Niemeyer Verlag. 